\title{
Evaluation of the utilization management programme at Salmaniya Medical Complex, Bahrain
}

B.E.A.H. Fateha'

$$
\begin{aligned}
& \text { تأثي برنامج إدارة الاستخدام على متوسط لمرة الإتامة بمجمع السلمانية الطبي بالبحرين } \\
& \text { بهاء الثدين عبد المبميد نتيحة }
\end{aligned}
$$

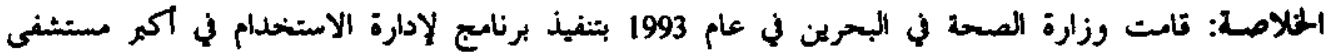

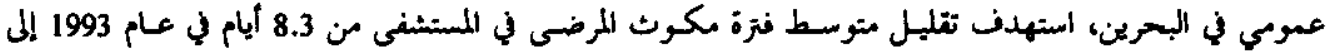

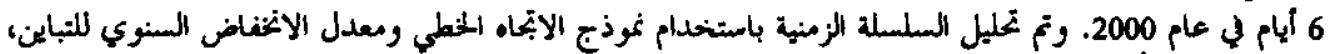

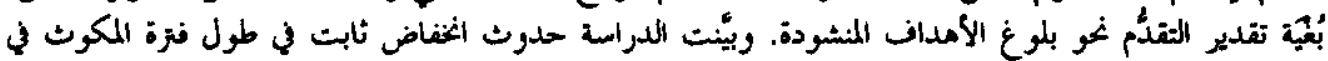

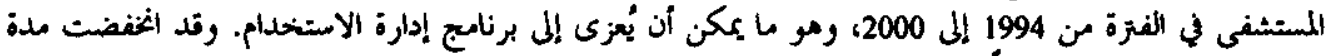

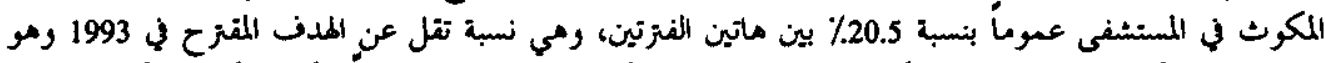

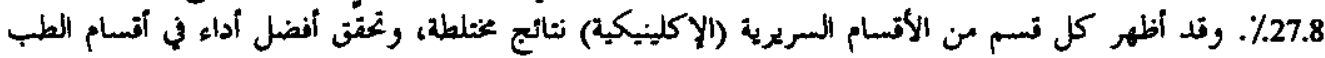

$$
\text { والمراسة }
$$

ABSTRACT In 1993, the Ministry of Health in Bahrain implemented a utilization management programme at the largest public hospital in the country, aimed at reducing patients' mean length of stay from 8.3 days in 1993 to 6.0 days in 2000 . Time series analysis, using linear trend modelling and the annual disparity reduction rate, were used to estimate performance towards achieving the targets. The study found that the length of stay declined consistently between 1984 and 2000, with a steeper dectine in the period 1994-2000, which could be attributed to the utilization management programme. Overall, length of stay was reduced by $20.5 \%$ between the two periods, short of the target $27.8 \%$ proposed in 1993 . Individual clinical departments showed mixed results, with better performance demonstrated by the Departments of Medicine and Surgery.

Evaluation du programme de gestion de l'utilisation des ressources au Complexe médical Salmanlya (Bahreïn)

RESUME En 1993, le Ministère de la Santé de Bahreïn a mis en couvre un programme de gestion de l'utilisation des ressources dans le plus grand hôpital public du pays, visant à réduire la durée moyenne de séjour des patients de 8,3 jours en 1993 à 6,0 jours en 2000. Pour évaluer les résultats obtenus dans la réalisation de ces objectifs, on a utilisé l'analyse des séries chronologiques, avec la modélisation linéaire, et le taux annuel de réduction des disparités. L'étude a révélé que la durée du séjour a diminué constamment entre 1984 et 2000, avec un recul plus marqué pendant la période 1994-2000, ce qui pourrait être attribué au programme de gestion de l'utilisation des ressources. Dans l'ensemble, la durée du séjour a été réduite de $20,5 \%$ entre 1993 et 2000, ce qui est inférieur à l'objectif de 27,8\% proposé en 1993. Les différents services cliniques ont montré des résultats mitigés, avec une meilleure performance affichée par les services de médecine et de chirurgie.

'Office of Medical Review, Ministry of Health, Bahrain.

Received: 12/07/01; accepted: 26/10/01

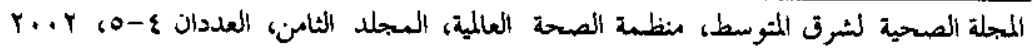




\section{Introduction}

Many studies from countries with different health systems, for example Canada, United States of America, Italy and Denmark, have reported on the use of acute care hospital beds. They concluded that a large percentage of days of care, ranging from $22.8 \%$ to $37.3 \%$, are inappropriate as well as up to $14.2 \%$ of all admissions [ $1-4]$.

In August 1993, the Ministry of Health in Bahrain introduced a hospital-wide use management programme aimed at increasing the efficiency and effectiveness of services through regular evaluations and reviews of hospital services [5]. Among the targets of the programme was reducing the mean length of stay (LOS) at Salmaniya Medical Complex from 8.3 days in 1993 to 6.0 days by the year 2000 , equivalent to a reduction of $27.8 \%$. The hospital is the largest public acute general hospital in Bahrain, with a total capacity exceeding 930 beds [6]. The hospital also caters for many long-stay patients owing to the lack of intermediate care facilities in Bahrain.

The Office of Medical Review at the Ministry of Health set target LOS for each department after consultations with key members of the medical staff, and taking account of the local and regional LOS data and the patient mix in Bahrain. The utilization management programme has been focusing on the appropriateness of admission to the hospital and monitoring the continuous stay of patients through a concurrent review of medical records $[7,8]$. Patients are assigned a preliminary LOS on admission, based on their diagnosis and age group. The assigned LOS functions only as a reference to the medical staff, with no efforts made to enforce it. After discharge of patients from the hospital, the data on actual LOS are recorded and analysed regularly by the Office of Medical Review to estimate the trend and to make the necessary modifications in the reference tables of LOS.

This study aimed to evaluate the effect of the utilization management programme since its introduction in 1993 on the LOS at the hospital. The study also evaluated the performance of the hospital and individual departments towards achieving their respective objectives.

\section{Methods}

The data for the study were based on the reported annual average LOS for the whole hospital and for each department from 1984 to 2000 . Time series analysis using the linear trend model (LTM) was produced for LOS data in these years. A forecast of data for 1994-2000 was developed based on the LOS trend for the 10-year period before implementing the utilization management programme (1984-1993). Another forecast was constructed for the period 1994-2000 to evaluate progress towards achieving the pre-set objectives of the programme. This used the annual disparity reduction rate (DRR) [9-11] to estimate the expected year-to-year LOS based on preset targets for each department.

The annual DRR was developed at the Overseas Development Council under the direction of Morris D. Morris and James P. Grant. It is computed according to the following formula:

$$
\begin{aligned}
\text { annual DRR }= & {[(\text { disparity at the end of }} \\
& \text { period/disparity at begining } \\
& \text { of period } \left.)^{1 / t}-1\right] \times 100
\end{aligned}
$$

where $t$ represents the time gap between the beginning and end of the period.

A positive annual DRR indicates narrowing of the disparity, while a negative

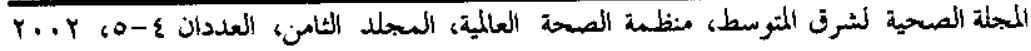


annual DRR indicates widening of the disparity. For example, the target LOS for the whole hospital was 4.5 days, the observed LOS for the base year of 1993 was 8.3 and for 2000 was 6.6. Therefore $t=7$ and the computed annual DRR $=-8.1 \%$, signifying a positive performance of $8.1 \%$ annually in reducing the gap between the LOS in 1993 and 2000.

The paired-samples $t$-test was used to identify whether or not the difference between LOS data generated by the LTM, LTM forecast and annual DRR forecast were statistically significant. Minitab and SPSS statistical packages were used for the analysis and forecast.

\section{Results}

The observed LOS for the whole hospital and its major clinical departments for the years 1984 (start of preprogramme period), 1993 (end of preprogramme period), 1994 (start of programme) and 2000 (end of review period) are shown in Table 1 .

Figures 1-7 show the actual 'observed LOS' for 1984-2000 and the LOS lines generated by the three estimation models for the period 1994-2000:
- the 'LTM' line based on actual data for the period 1984-2000;

- the 'LTM forecast' line for 1994-2000 based on preprogramme data; and

- the 'DRR forecast' line representing the expected achievement for the same period.

The whole hospital showed a decline in the average LOS during the review period (Figure 1). The LTM analysis showed the trend for the LOS on a fitted line and generated forecast LOS for the period 19942000 based on the preprogramme data. The accuracy of the fitted line was demonstrated by three measures: mean absolute percentage error (MAPE), mean absolute deviation (MAD) and mean squared deviation (MSD), which were computed for all departments. MAPE error ranged between 3.49 and 10.90 , while MAD and MSD ranged between 0.07 and 0.94 , which indicated a good fit of the LTM line.

The average LOS for the whole hospital showed a decline that was better than the forecast line generated by the LTM (Figure 1). The forecasted data for 1994-2000 indicated that the LOS for the whole hospital would have been 8.3 days in 1994 and 7.0 days in 2000 whereas the LTM data were

Table 1 Observed mean length of stay (LOS) by department during 1984-2000 at Salmaniya Medical Complex, Bahrain

\begin{tabular}{|c|c|c|c|c|c|c|c|}
\hline \multirow{2}{*}{ Year } & \multirow[b]{2}{*}{ All } & \multirow[b]{2}{*}{ Medicine } & \multicolumn{3}{|c|}{ Mean LOS (days) } & \multirow[b]{2}{*}{ Paediatrics } & \multirow[b]{2}{*}{ Ophth } \\
\hline & & & Surgery & ENT & Ob/gyn & & \\
\hline 1984 & 9.8 & 12.6 & 13.4 & 9.3 & 7.4 & 8.5 & 12.5 \\
\hline 1993 & 8.3 & 11.3 & 9.1 & 4.7 & 5.3 & 6.2 & 6.9 \\
\hline 1994 & 7.5 & 10.0 & 8.0 & 3.8 & 5.4 & 5.2 & 6.1 \\
\hline 2000 & 6.6 & 9.1 & 8.2 & 3.3 & 4.2 & 5.5 & 7.0 \\
\hline
\end{tabular}

Source: Annual Statistics, Ministry of Health, Bahrain, 1985-2000 (with permission).

$E N T=$ Ear, nose and throat. Ob/gyn = obstetrics and gynaecology.

Ophth = ophthaimology. 


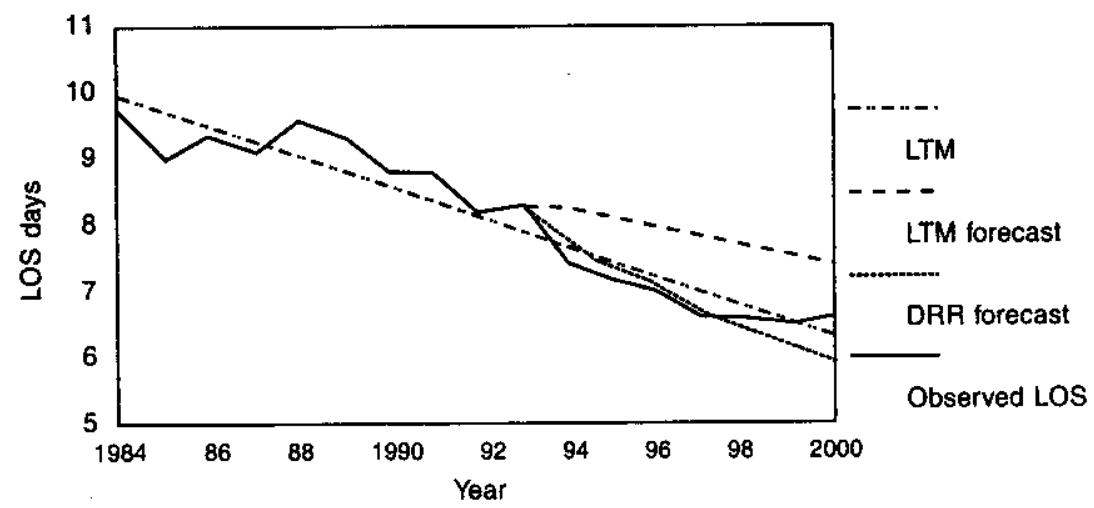

Figure 1 Observed length of stay (LOS) and forecasts based on the linear trend model (LTM) and disparity reduction rate (DRR): all departments

Fitted trend equation: $Y t=10.1619-0.226 \times t$

7.7 and 6.3 days. The difference in the forecasted data and figures generated by the model following the implementation of the programme was $6.9 \%$ in 1994 and $14.6 \%$ in $2000(P<0.001)$. The overall reduction in the length of stay between 1993 and 2000 according to the LTM was $20.7 \%$, and the observed LOS was reduced by $20.5 \%$. This achievement, nevertheless, was short of the $27.8 \%$ target set in 1993 . Furthermore, the observed annual DRR for the whole hospital was $-8.12 \%$ which was less than the estimated annual DRR rate of $-12.4 \%$, required to achieve the objective of 6.0 days by the year 2000 . The difference between the LTM and DRR forecasts was statistically significant $(P=0.029)$.

The Department of Medicine showed a steeper decline in the observed LOS compared with the forecast (Figure 2). The difference ranged from $7.7 \%$ in 1994 to $16.1 \%$ in 2000 . The overall reduction in the LOS between 1993 and 2000 for the department according to the LTM was $19.7 \%$, and the observed reduction in the
LOS between the two periods was $19.5 \%$ $(P<0.001)$. However, the observed DRR for the department was $-6.0 \%$, which was short of the expected DRR of $-15.1 \%$, required to achieve the objective of 7.0 days by the year 2000 . The difference between the LTM forecast and the annual DRR forecast was statistically significant $(P=$ 0.011).

The Department of Surgery showed a steeper decline in the observed LOS compared with the forecast (Figure 3). The difference between the LTM and the forecast LOS data ranged from $4.9 \%$ in 1994 to $10.3 \%$ in $2000(P<0.001)$. The overall decline in LOS between 1993 and 2000 according to the LTM was $29.4 \%$, while the observed LOS was $9.9 \%$. The achieved LOS of 6.7 days according to the LTM was better than the forecast of 7.5 , but short of the ARR estimated target of 5.0 days. The target required an estimated annual DRR of $-20.8 \%$, while the observed DRR was $-2.7 \%$. The difference between the LTM

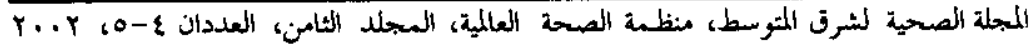




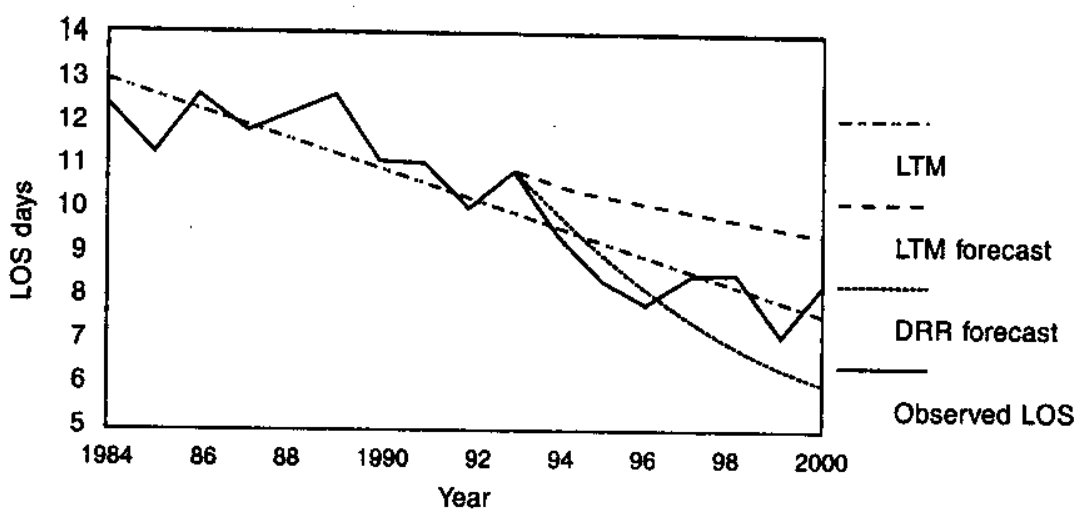

Figure 2 Observed length of stay (LOS) and forecasts based on the linear trend model (LTM) and disparity reduction rate (DRR): Department of Medicine

Fitted trend equation: $Y t=7.06-0.1760 \times t$

forecast and the DRR forecast was statistically significant $(P<0.001)$.

The Department of Ear, Nose and Throat (ENT) showed a decline in the LOS of $29.8 \%$ between 1993 and 2000 (Figure 4). However, the LTM forecast figures were higher than the model by $7.6 \%$ in 1994, and the difference widened to $55.7 \%$ in $2000(P<0.001)$. The estimated DRR required to achieve an $\operatorname{LOS}$ of 2.5 days by 2000 was $-23.3 \%$, while the observed DRR between 1993 and 2000 was $-7.9 \%$. The difference between the LTM and DRR forecasts was statistically significant $(P<$ 0.001 ).

The Department of Obstetrics and Gynaecology (previously the Maternity Unit) had shown a decline in the LOS between 1993 and 2000 that amounted to $20.8 \%$. However, the department should have achieved better results as indicated by the forecast. According to the LTM figures, the department fell short of the forecast data by $7.6 \%$ and $18.4 \%$ for 1994 and 2000 respectively (Figure 5 ). The difference be- tween LOS generated by the LTM and the LTM forecast was statistically significant $(P<0.001)$. The estimated DRR required to achieve an LOS of 3.0 days was $21.8 \%$, while the observed DRR was $6.9 \%$. The difference between the LTM and DRR forecasts was statistically significant $(P<0.001)$.

The Department of Paediatrics showed an overall decline of $11.3 \%$ in the observed LOS between 1993 and 2000 (Figure 6). Data analysis, however, indicated that the department fell short of the expected LOS, as indicated by the forecast line, which was above the LTM-LOS fitted line. The differences between LOS generated by the fitted LTM and forecast lines were $8.5 \%$ and $22.2 \%$ for 1994 and 2000 respectively $(P<$ 0.001 ). The expected annual DRR required to achieve the preset target of 4.0 days by 2000 was $-15.3 \%$, while the observed DRR was $-3.5 \%$. The difference between the LTM and DRR forecasts was statistically significant $(P<0.001)$. 


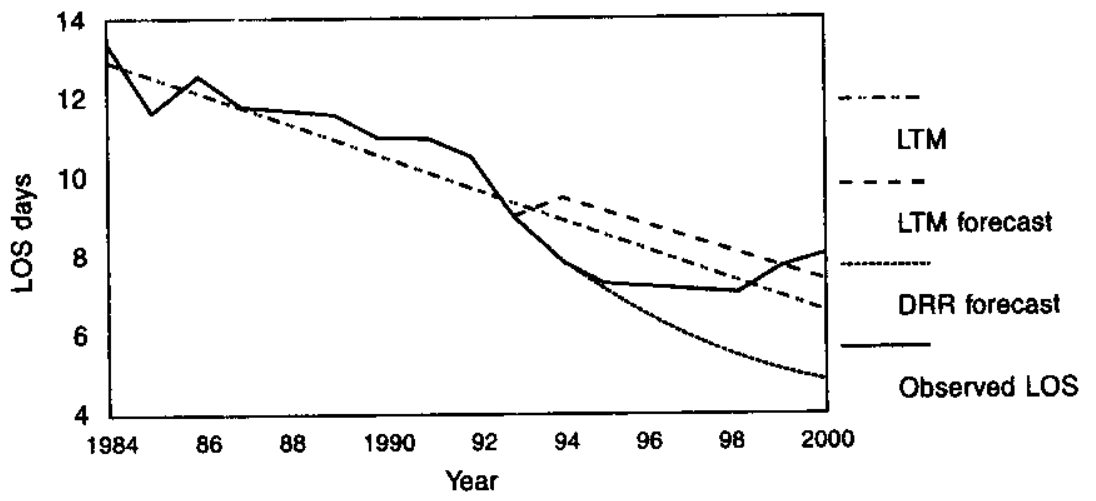

Figure 3 Observed length of stay (LOS) and forecasts based on the linear trend model (LTM) and disparity reduction rate (DRR): Department of Surgery Fitted trend equation: $Y t=13.4044-0.394608 \times t$

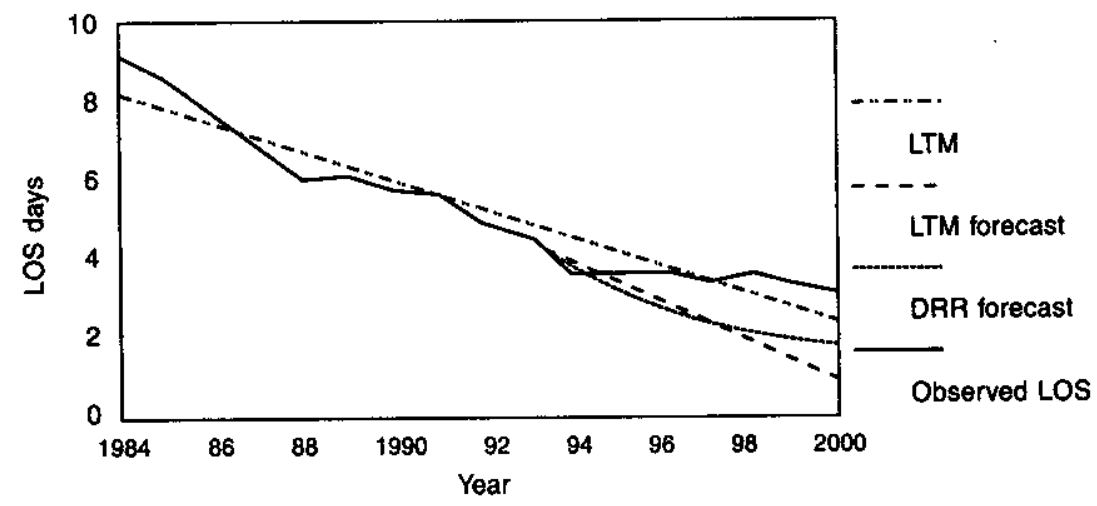

Figure 4 Observed length of stay (LOS) and forecasts based on the linear trend model (LTM) and disparity reduction rate (DRR): Department of Ear, Nose and Throat Fitted trend equation: $Y t=8.69559-0.362255 \times t$

The Department of Ophthalmology was the only department that failed to show any decline in the observed LOS following the implementation of the programme, despite having an overall decline between 1984 and 2000 (Figure 7). The LOS generated by the
LTM in 1994 and 2000 were 7.7 and 5.7 days, higher than the LTM forecast of 6.1 and 2.4 days respectively $(P<0.001)$. The required DRR to achieve a preset target of 4.0 days was $-17.7 \%$, while the observed DRR showed marginal change of $+0.4 \%$.

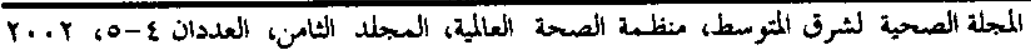




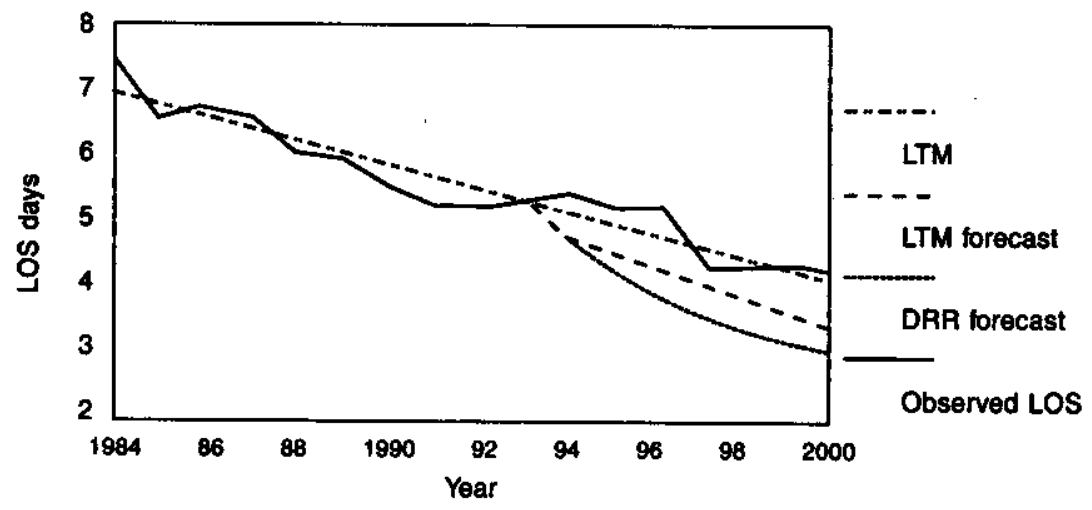

Figure 5 Observed length of stay (LOS) and forecasts based on the linear trend model (LTM) and disparity reduction rate (DRR): Department of Obstetrics and Gynecology, Fitted trend equation: $Y t=7.06029-0.175980 \times t$

The difference between the LTM forecast and DRR forecast was statistically significant $(P<0.001)$.

\section{Discussion}

Hospital efficiency is closely related to utilization levels and length of stay [1]. With the emerging trend to shift financial risks from payer to provider, hospitals in many countries are striving to reduce the LOS and achieve optimum use of resources. The LOS has been decreasing dramatically in acute general hospitals. A major review study in the United States revealed that the average LOS decreased from 8.5 days in late 1960 to under 6 days in 1986 [12]. The findings of the present study were in concordance with these reports. The utilization management programme that commenced in 1993 led to an accelerated, and statisti- cally significant, decline in the LOS that was greater than the expected reduction based on historical data prior to the utilization management programme.

While some departments did not show a significant reduction in the LOS beyond the projected historical data, the major Departments of Medicine and Surgery were successful in reducing the LOS below the forecast figures, which subsequently led to an overall decline in LOS for the whole hospital by $20.5 \%$ between 1993 and 2000 . This was in agreement with many studies, which reported improvements in the LOS by up to $22 \%$ following the introduction of utilization management measures [13]. Discussions with many consultants at the ENT and Ophthalmology departments, which did not show any significant decline in the LOS, indicated a tendency to keep patients in hospital longer than necessary in order to 


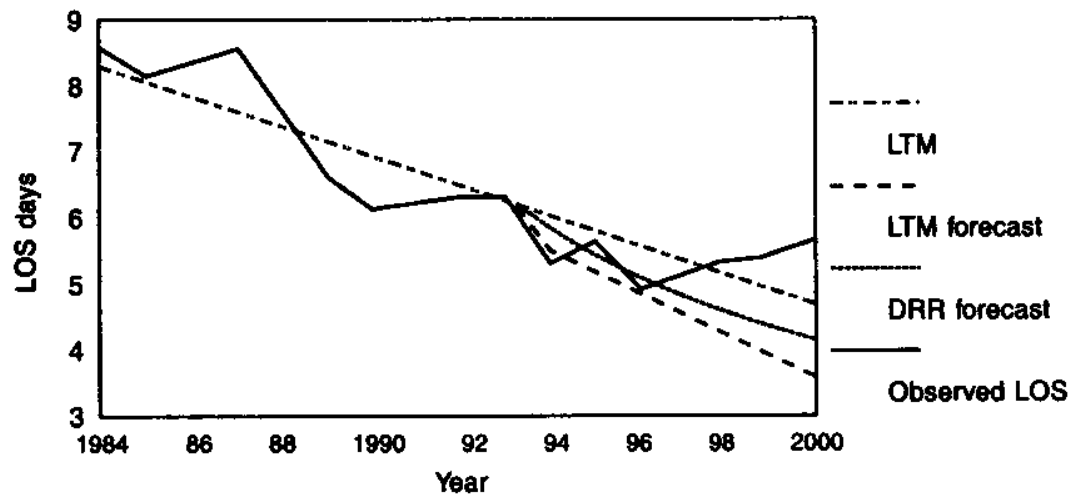

Figure 6 Observed length of stay (LOS) and forecasts based on the linear trend model (LTM) and disparity reduction rate (DRR): Department of Paediatrics Fitted trend equation: $Y t=8.47206-0.232843 \times t$

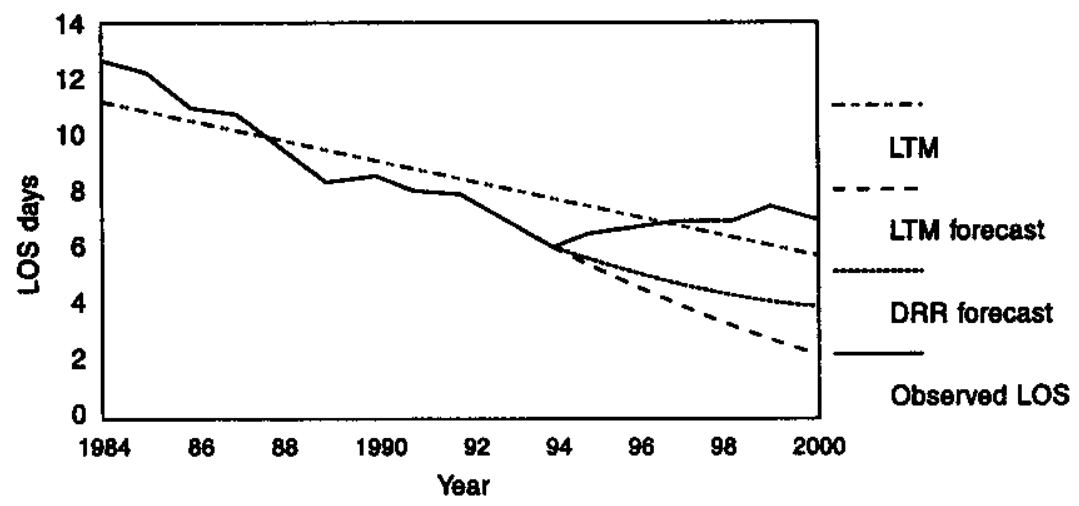

Figure 7 Observed length of stay (LOS) and forecasts based on the linear trend model (LTM) and disparity reduction rate (DRR): Department of Ophthalmology Fitted trend equation: $Y t=11.4640-0.340441 \times t$

prevent patients from other departments occupying beds. This impression was borne out by the high bed occupancy rate in the Departments of Medicine and Surgery, which exceeded $90 \%$ in the second half of the 1990s $[5,14-16]$.
The decline in the LOS was short of the expected target. We therefore believe that Saimaniya Medical Complex needs to continuously review and update the existing utilization management programme. Specific measures to improve the utilization

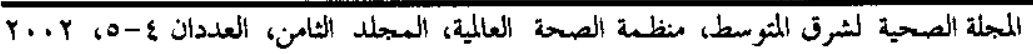


management programme-such as compiling individual physician profiles, establishing protocols for clinical diagnoses, admissions and continuous stay, and carrying out policy reviews of admission and discharge - should lead to a further decline in the LOS. These measures were found to be successful in reducing the LOS by diagnosis, and consequently the overall LOS in the hospital [17-20].

On the other hand, some individual departments were showing slight but consistent increases in the observed LOS during the period 1998-2000. This was similar to reports from other studies that the LOS in hospitals is creeping upwards. The reason for this increase is currently under debate, and may be due to a corresponding increase in the severity of conditions being treated in acute care facilities [21-23]. This calls for other initiatives to reduce the LOS, as well as continuous evaluation of the existing utilization management programmes.

\section{Conclusion}

The introduction of a utilization management programme at Salmaniya Medical Complex in 1993 has had a positive impact on the decline of the overall LOS at the hospital. The LOS had been declining since 1984, but the decline accelerated after 1994 and this could be attributed to the utilization management programme. The observed LOS declined by $20.5 \%$ between 1993 and 2000. However, the improvement was not consistent across departments. The major Departments of Medicine and Surgery showed a decline in the LOS that was better than the forecast. Other departments did not perform as well as expected towards achieving a reduction in the LOS that would match the forecast. The study calls for renewed efforts to reduce the LOS, and thus improve utilization of the available resources at the hospital.

\section{References}

1. Doyle $M$ et al. The efficiency of acute care bed utilization in Newfoundland and Labrador. Healthcare management forum, 1998, 11(3):15-25.

2. Kaplow $M$ et al. Managing patient length of stay better using an appropriateness tool. Healthcare management forum, 1998, 11(2):13-20.

3. Kalant $\mathrm{N}$ et al. How valid are utilization review tools in assessing appropriate us $\theta$ of acute care beds? Canadian Medical Association joumal, 2000, 162(13): 1809-13.

4. Angelillo I et al. Appropriateness of hospital utilization in Italy. Public health, 2000, 114(1):9-14.

5. Brown G, Bopp K, Soper M. Managed care's evolving role. In: Taylor RJ, Taylor
SB, eds. The AUPHA manual of health services management. Aspen, Aspen Publications, 1994:140.

6. Health Statistics 2000. Bahrain, Ministry of Health Publications, 2001.

7. Fakhro A, Fateha B. Establishing criteria and norms for utilization management at Salmaniya medical center. Joumal of the Bahrain Medical Society, 1991, 3(3): 157-60.

8. Fateha B. Utilization review programme. Journal of the Bahrain Medical Society, 1991, 3(3):131-2.

9. Grant JP. Disparity reduction rates in social indicators: a proposal for measuring and targeting progress in meeting basic needs. Monograph no. 11. Washington 
DC, Overseas Development Council, 1978.

10. Greentree T, Philips R. The PQLI and the DRR: new tools for measuring development progress. Communiqué 4 . Washington DC, Overseas Development Council, 1979.

11. Liser F. Statistical annexes. In: MM McLaughlin, ed. The United States and world development: agenda 1979. New York, Praeger, 1979:125-144.

12. Pokras $\mathrm{R}$ et al. Trends in hospital utilization, 1965-1986. American journal of public health, 1990, 80(4):488-90.

13. Kay $R$, Wadsworth $T$. Utilizing physician leadership to reduce length of stay. Medical group management journal, 1995, 42(5):66-74.

14. Health statistics 1999. Bahrain, Ministry of Health Publications, 2000.

15. Health statistics 1998. Bahrain, Ministry of Health Publications, 1999.

16. Health statistics 1996-1997. Bahrain, Ministry of Health Publications, 1998.

17. Weingarten JP, Clay JC, Heckert DA. Impact of socioeconomic status on healthcare utilization: factors influencing length of stay. Journal of health and human services administration, 1997 19(4):384-409.
18. Esmail A. Development of the paediatric appropriateness evaluation protocol for use in the United Kingdom. Journal of public health medicine, 2000, 22(2): 224-30.

19. Evans J, Hwang Y, Nagarajan N. Physicians' response to length-of-stay profiling. Medical care, 1995, 33(11): 110619.

20. Ross G, Johnson D, Castronova F. Physician profiling decreases inpatient length of stay even with aggressive quality management. American journal of medical quality, 2000, 15(6):233-40.

21. Editorial. Patients' increased severity of illness drives up LOS around the country. Hospital case management, 1999 , 7(5): 81-4.

22. Stineman $M$ et al. Functional gain and length of stay for major rehabilitation impairment categories. Patterns revealed by function related groups. American journal of physical and medical rehabilitation, 1996, 75(1):68-78.

23. lezzoni $L$ et al. Does severity explain differences in hospital stay for pneumonia patients? Journal of health services research policy, 1996, 1(2):65-76. 